\title{
Evaluation of H2 Getter Materials for Use in the TRUPACT-II
}

by

R. R. Livingston

Westinghouse Savannah River Company

Savannah River Site

Aiken, South Carolina 29808

M. L. Crowder

J. M. Duffey

This paper was prepared in connection with work done under the above contract number with the U.S.

Department of Energy. By acceptance of this paper, the publisher and/or recipient acknowledges the U. S. Government's right to retain a nonexclusive, royalty-free license in and to any copyright covering this paper, along with the right to reproduce and to authorize others to reproduce all or part of the copyrighted paper. 


\section{DISCLAIMER}

This report was prepared as an account of work sponsored by an agency of the United States Government. Neither the United States Government nor any agency thereof, nor any of their employees, makes any warranty, express or implied, or assumes any legal liability or responsibility for the accuracy, completeness, or usefulness of any information, apparatus, product, or process disclosed, or represents that its use would not infringe privately owned rights. Reference herein to any specific commercial product, process, or service by trade name, trademark, manufacturer, or otherwise does not necessarily constitute or imply its endorsement, recommendation, or favoring by the United States Government or any agency thereof. The views and opinions of authors expressed herein do not necessarily state or reflect those of the United States Government or any agency thereof.

This report has been reproduced directly from the best available copy.

Available to DOE and DOE contractors from the Office of Scientific and Technical Information, P.O. Box 62, Oak Ridge, TN 37831; prices available from (615) 576-8401.

Available to the public from the National Technical Information Service, U.S. Department of Commerce, 5285 Port Royal Road, Springfield, VA 22161. 


\section{DISCLAIMER}

Portions of this document may be illegible in electronic image products. Images are produced from the best available original document. 


\title{
Evaluation of Hydrogen Getter Materials \\ for Use in the TRUPACT-II
}

\author{
Ronald R. Livingston \\ Mark L. Crowder \\ Jonathan M. Duffey
}

September 1999

Westinghouse Savannah River Company Aiken, SC 29808 


\title{
Evaluation of Hydrogen Getter Materials \\ for Use in the TRUPACT-II
}

\author{
Ronald R. Livingston \\ Mark L. Crowder \\ Jonathan M. Duffey
}

Issued: September 1999

\section{Approvals}

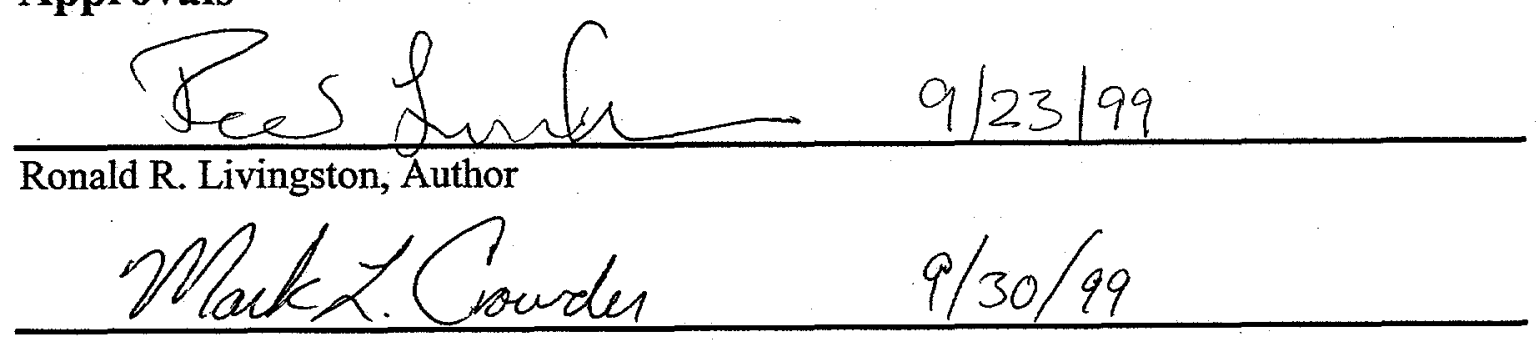

Mark L. Crowder, Author

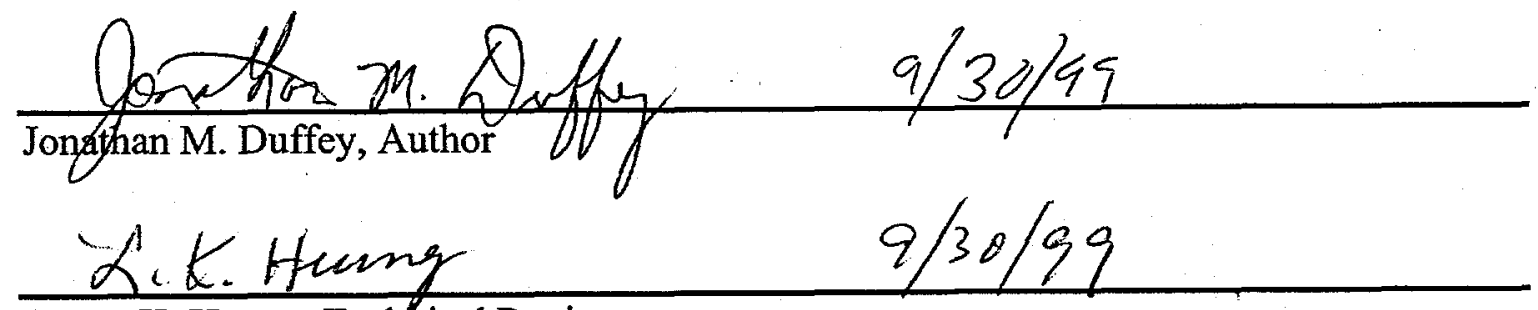

Leung K. Heung, Technical Reviewer

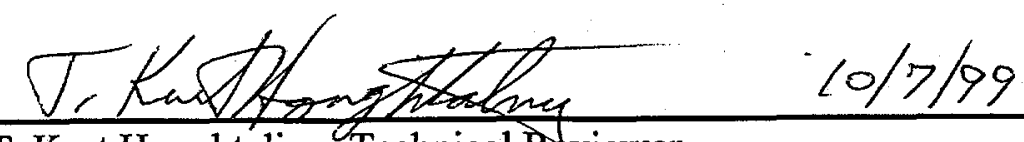

T. Kurt Houghtaling, Technical Reviewer 
Section

\section{Table of Contents}

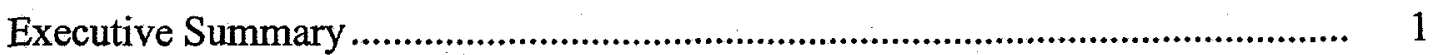

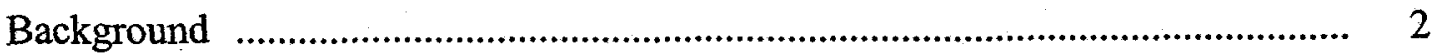

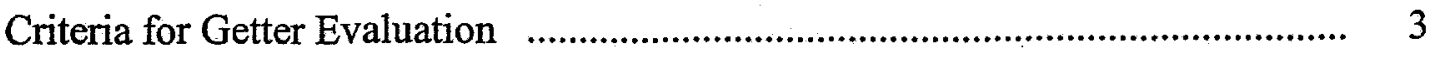

NRC Requirements ................................................................................. 3

Evaluation Criteria .................................................................................. 4

Screening Criteria ........................................................................................... 6

Ranking Criteria ............................................................................................ 6

Description of Getter Materials

Group A - Unsaturated Organic with Hydrogenation Catalyst $\quad$................... 7

Group B - Recombination Catalysts ……........................................................ 7

Group C - Metal Hydrides …………............................................................. 8

Group D - Composite Materials and Layered Products ............................... 8

Impact of Operating Parameters on Getter Design .................................................. 8

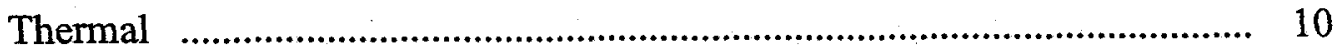

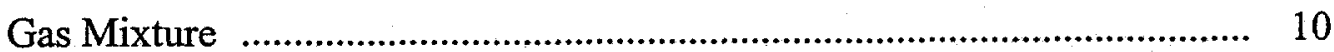

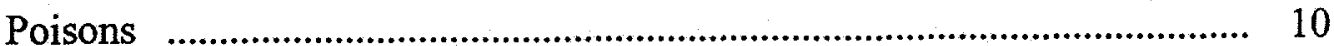

$\mathrm{H}_{2}$ Production Rates ............................................................................. 11

Evaluation of Current and Developing Technologies ......................................... 11

Dealing with Gas and Vapor Poisons ……................................................... 12

Evaluation of Composite Systems ............................................................... 14

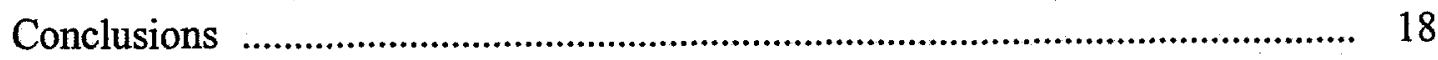

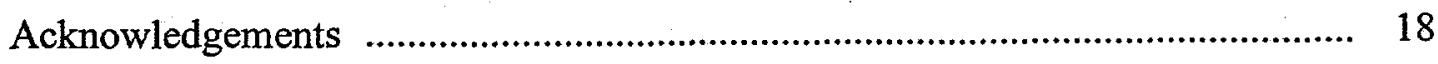

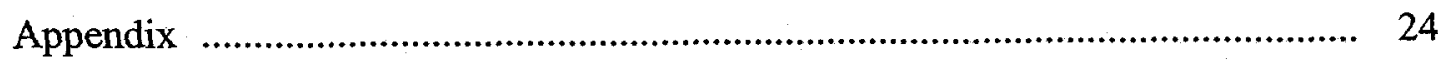

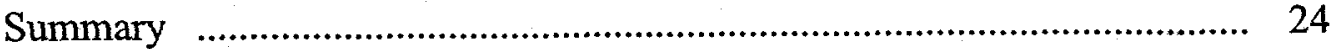

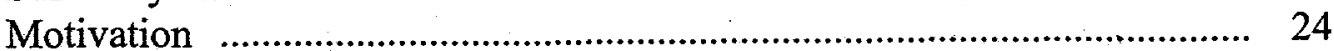

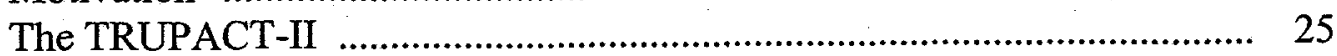

Hydrogen Generation ................................................................................ 26

Design Criteria ……................................................................................. 26

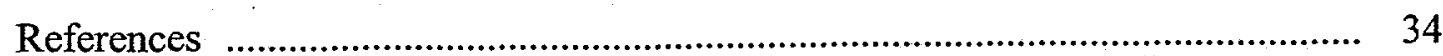




\section{List of Tables}

Page

Table 1 Impact of Operating Parameters on Getter Function and Design ...... 9

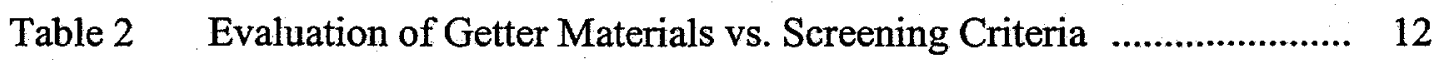

Table 3 Evaluation of DEB and SGMH Getter Systems vs. Ranking Criteria.......................................................... 16

Table A-1 Wattage Limits per 55-Gallon Drum for Analytical Shipping Categories

\section{List of Figures}

Figure 1 Side view cross-section of TRUPACT-II containing drums $\quad$........ 19

Figure 2 Top view cross-section of TRUPACT-II containing drums $\quad . . \ldots . . .20$

Figure $3 \quad$ Standard Waste Box …............................................................. 21

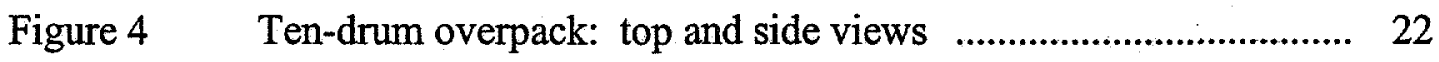

Figure $5 \quad$ van't Hoff plots (desorption) for various hydrides ........................ 23 


\title{
Evaluation of $\mathrm{H}_{2}$ Getter Materials for Use in the TRUPACT-II
}

\author{
Ronald R. Livingston, Mark L. Crowder, and Jonathan M. Duffey
}

\section{Executive Summary}

Savannah River Site (SRS) has many waste drums containing Pu-238 that exceed the currently allowed wattage for transportation in the Transuranic Package Transporter-II (TRUPACT-II). By eliminating layers of confinement in waste drums and using getters to remove hydrogen gas, the TRUPACT-II waste loading can be increased significantly, with the potential of reaching the package's 40 -watt thermal limit. The cost savings associated with increasing the waste loading are enormous, and can be measured by reduced numbers of shipments, required processing facilities, and years of effort.

To support the decision-making process and provide a good starting point for future development efforts at SRTC, the design requirements for a getter system to be used in the TRUPACT-II were compiled and are discussed in detail in the Appendix. The key points from the Appendix, along with an evaluation of getter materials, are presented here. The purpose of this document is three-fold: 1) to establish criteria for rating getter materials for use in the TRUPACT-II, 2) to review current and developing technology options against these criteria, and 3) to recommend the most likely material(s) to meet the design requirements.

Based on the Appendix, the successful hydrogen getter for the TRUPACT-II must be able to maintain the concentration of $\mathrm{H}_{2}$ below $5 \%$ inside the TRUPACT-II for a variety of transuranic-contaminated waste types. It must function under these conditions: 1) internal pressures up to $50 \mathrm{psig} ; 2$ ) temperatures from -20 to $170^{\circ} \mathrm{F} ; 3$ ) headspace gas and vapor compositions containing up to $500 \mathrm{ppm}$ flammable volatile organic compounds (VOCs), higher levels of nonflammable VOCs, and potential poisons such as hydrogen sulfide, carbon monoxide, etc.; 4) presence or absence of oxygen; 5) briefly applied vacuum conditions; and 6) presence of water vapor. In addition, the successful getter technology must withstand some level of radiation dose and fit well physically within the TRUPACT-II. Ideally, the getter will not significantly contribute to the TRUPACT-II weight limit.

These design requirements were combined with issues of cost, state of development, and other factors to evaluate the wide range of getter materials available. Of the getter materials evaluated, composite getter materials are the most promising technology for maintaining safe hydrogen levels in the TRUPACT-II. Of these, the highest-rated technology in this study is a material called sol-gel metal hydride (SGMH). Sol-gel metal hydrides provide good protection against poisons; generate relatively low amounts of heat, can be recycled and reused, and are not expected to generate water. In addition, more than one metal can be included in a SGMH package, providing a wide range of operational flexibility. 
Although SGMHs minimize the impact of some poisons, overcoming the impact of poisons on getter function remains the biggest challenge for getter use in the TRUPACTII environment. To overcome this limitation, further development of a composite getter is recommended. The suggested path forward on getter development calls for further materials characterization and pilot-scale studies on getter system implementation.

\section{Background}

The TRUPACT-II is a large type B packaging developed for the transportation of Transuranic (TRU) Waste from the Department of Energy (DOE) facilities across the United States (US) to the Waste Isolation Pilot Plant (WIPP) in Carlsbad, New Mexico. TRU waste commonly contains a variety of organic and inorganic materials like paper, plastic, steel, glass, cloth and sludge that are contaminated with TRU elements (atomic number $>92$ ) like plutonium and americium. The safe operating limits for the TRUPACTII are established as part of a safety evaluation coordinated by DOE to allow Nuclear Regulatory Commission (NRC) certification of the shipping container. ${ }^{1}$

Interaction of radiation from the TRU elements with the waste matrix results in decomposition of the waste and production of non-radioactive gaseous by-products. These radiolysis products include gases and vapors such as $\mathrm{H}_{2}, \mathrm{O}_{2}, \mathrm{CO}_{2}, \mathrm{CO}, \mathrm{CH}_{4}$, and $\mathrm{HCl}^{2-5}$ In addition to radiolysis gases and vapors, VOCs such as trichloroethylene (TCE) and acetone may contribute to the total gas phase composition. The Safety Analysis Report for the TRUPACT-II Shipping Package (TRUPACT-II SARP') limits the $\mathrm{H}_{2}$ concentration to $5 \%$ by volume to prevent the formation of flammable hydrogen/gas mixtures. Because the amount of $\mathrm{H}_{2}$ generated in TRU waste is a function of the waste type and radioactive decay energy, operating limits have been established for each waste type. These limits on decay energy are expressed in terms of watts to allow end-user flexibility in loading each TRUPACT-II for shipment.

The TRUPACT-II has an overall limit of 40 watts in radioactive decay energy based on the package's ability to dissipate the heat. The regulatory upper temperature inside the TRUPACT-II is $170^{\circ} \mathrm{F}$, which includes heating due to the time the package spends in direct sunlight on hot days. The character of TRU waste matrices and the energy of some radioactive contamination (e.g. $\mathrm{Pu}-238$ ) prevent the package from being loaded at the 40watt limit because of $\mathrm{H}_{2}$ accumulation. Frequently, the waste content is restricted to less than one-tenth of the certified limit (in many cases, 3 watts ${ }^{1}$ ), because of the $5 \% \mathrm{H}_{2}$ limit. The current SRS waste inventory includes about 7000 drums of waste contaminated with $\mathrm{Pu}-238$. More than half of these contain greater than 6 grams of Pu-238, ${ }^{6}$ which decays at a rate of 0.56 watts/gram. Hence, many individual SRS drums exceed the current wattage limit for a full TRUPACT-II payload. Most of these drums cannot be shipped without repackaging and the subsequent costly increase in number of required shipments.

To take full advantage of the 40-watt limit for decay heat in the TRUPACT-II, the DOE's Mixed Waste Focus Area (MWFA) and the DOE Carlsbad Operations Office are working 
to develop technology to increase the allowed waste loading. ${ }^{7}$ Two complementary approaches are being taken. The first is to repackage waste to minimize the number of confinement layers. This means that the plastic bags commonly used to contain TRU waste will be altered. The use of vents or other designs will allow diffusion of $\mathrm{H}_{2}$ through the bag and will reduce $\mathrm{H}_{2}$ build-up in the centers of bagged volumes. (Note: The $5 \%$ limit applies to the small, internal volumes in addition to the overall package containment.) Once this step is implemented for new waste being generated, the $\mathrm{H}_{2}$ can move freely out of the inner bags and into the storage drum. Each storage drum also contains a vent so that $\mathrm{H}_{2}$ can move similarly into the large TRUPACT-II inner containment vessel (ICV). See Figures 1 and 2. Implementing this step allows waste limits to be calculated based on $\mathrm{H}_{2}$ concentration in the large $\mathrm{ICV}$, which has a minimum void volume of 2450 liters with 14 completely filled storage drums. ${ }^{1}$ The minimum void volume is slightly different for the two other packaging configurations that are anticipated - the ten-drum overpack and the standard waste box. ${ }^{1}$ See Figures 3 and 4.

A complementary approach to further increase waste wattage limits is to remove the $\mathrm{H}_{2}$ from the ICV by reaction with or absorption by another material. This removal step is referred to as "gettering" $\mathrm{H}_{2}$. By combining $\mathrm{H}_{2}$ with a getter material as it is generated, it is possible to maintain the $\mathrm{H}_{2}$ concentration below the $5 \%$ limit. The optimum placement of getter material (i.e., either loose or within a dedicated container, inside individual drums or within the ICV) has yet to be determined.

Many different materials and approaches can be taken to remove $\mathrm{H}_{2}$ from the gases accumulated within a package. The next section presents criteria used to evaluate hydrogen getters for use in the TRUPACT-II. Some of these criteria are absolute and are used to screen potential getter materials. Other factors are important, but not essential, and are used to rank getter materials that pass the screening requirements.

\section{Criteria for Getter Evaluation}

\section{$\underline{\text { NRC Requirements }}$}

The following excerpt ${ }^{8}$ summarizes the NRC concerns with use of getters to maintain $\mathrm{H}_{2}$ at a concentration of less than $5 \%$ in shipping containers.

\section{NRC Concerns with Use of Getters}

- Capacity: What is the getter's capacity relative to the potential total gas generated during one year?

- Pressure: What is the maximum normal operating pressure (MNOP) during one year? Is the getter's performance affected by pressure?

- Poisons: Are there any chemical constituents in the contents that could potentially poison the getter?

- Reversibility: Under what conditions will the getter release hydrogen and could these conditions occur during transport? 
- Temperature: What is the effective temperature range of the getter relative to the temperature conditions specified in $10 \mathrm{CFR} 71\left(-20\right.$ to $100^{\circ} \mathrm{F}$ plus solar insolation)?

- Humidity: What is the effect of water vapor on the getter? Will frozen getter still work?

- Location: Does the location of the getter matter? Consider stratification of the gasses.

- Thermal: Does the getter release/absorb heat? If so, is this factored into the thermal and structural analysis?

The tests required to respond to these issues, based on previous case history for shipment of failed Three Mile Island reactor core debris, will be quite extensive. ${ }^{9}$ After identification of design requirements, a process initiated by this document, an appropriate getter material or combination of materials can be selected, thereby reducing risks associated with NRC acceptance of the getter system.

The most difficult NRC concern to reconcile for implementation of a getter device is that of poisons. An important part of our ranking of technology options is based on the ability to engineer around the poison problem for each getter material.

\section{Evaluation Criteria}

An effective review of $\mathrm{H}_{2}$ getter technologies suitable for service in the TRUPACT-II ICV under regulatory conditions requires developing a list of getter evaluation criteria. The overall getter design consists of two principal parts: 1) the material that converts $\mathrm{H}_{2}$ to a non-flammable form and 2) the supporting device components. These components include parts such as a canister for holding the getter material, membranes to remove poisons, and metal fins for heat transfer. This document is directed primarily at helping identify the best-suited getter material, not the supporting components. As part of this review, a description of current getter technology is provided in sufficient detail that the reader may be able to independently rank the options.

Safety. The evaluation of device safety should include risks to workers, facilities, and the environment during manufacture, storage, use, and disposal. The selected technology must, first and foremost, be able to maintain the $\mathrm{H}_{2}$ concentration below $5 \%$ by volume under the rigorous conditions anticipated for the TRUPACT-II. These conditions are:

1) internal pressures up to $50 \mathrm{psig}$;

2) temperatures from $-20^{\circ}$ to $170^{\circ} \mathrm{F}$;

3) a wide variety of TRU-contaminated waste types;

4) headspace gas and vapor compositions containing up to $500 \mathrm{ppm}$ flammable volatile organic compounds (VOCs), higher levels of nonflammable VOCs, and potential poisons such as $\mathrm{H}_{2} \mathrm{~S}, \mathrm{CO}$, etc;

5) presence or absence of oxygen;

6) briefly applied vacuum conditions (to test TRUPACT-II seals); and

7) presence of water vapor (which may condense or freeze onto the getter surface). 
In addition, the successful getter package must withstand some level of radiation dose, fit well physically within the TRUPACT-II, and meet the TRUPACT-II weight limit (not anticipated to be a problem). Any getter technology that cannot function adequately under the above conditions should be excluded from consideration.

Cost. The selected technology must be cost effective to develop, implement, and maintain. Other expenses that should be evaluated include starting materials, maintenance, recycle and disposal. Because some of the $\mathrm{H}_{2}$ getters contain precious metals as catalysts or are expensive to prepare, the ability to recycle or regenerate the device is important. The value added by reuse must be offset by the cost of apparatus maintenance and qualification. The cost associated with implementing getter technology should also be kept in perspective of the overall TRU Waste programs; however, this assessment is left to the appropriate program office.

Materials Factors. Consideration must be given to the availability of starting materials. Selecting materials that can be readily produced by multiple manufacturers and have other industrial applications is a decided plus. The materials' characteristics should be known or easily determined to support apparatus design. The basic data that will be required include heat generated per mole of $\mathrm{H}_{2}$, the material density, melting point, operating temperature limits, shelf life, $\mathrm{H}_{2}$ capacity, reaction kinetics, and resistance to poisons. In addition, data on the pressure-temperature-composition relationship for different getter materials, including the degree of reversibility of $\mathrm{H}_{2}$ absorption, must be considered.

Ease of Design. Each of the materials factors will have to be supported by the apparatus design. Materials that release large amounts of heat or require protective membranes will need a more complicated supporting apparatus than materials that will function simply poured into a perforated container. Other design factors that must be considered are the size, shape, and weight of the getter package and the difficulty of assembly and maintenance.

State of Development. Because each of the materials to be used for gettering $\mathrm{H}_{2}$ in the TRUPACT-II ICV has some alternate application or development history, consideration should be given to these data. Materials that find broad application and have been used extensively in commercial applications are likely to have well known features and problems. For materials currently being developed, the level of funding and timetable for completion should be factored into the decision making process. In each case sufficient evidence for "proof of principle" is needed to include the material in theoretical apparatus designs.

It is possible to separate these criteria into two main categories: screening criteria and ranking criteria. Screening criteria are those which are essential to the successful function of an $\mathrm{H}_{2}$ getter in the TRUPACT-II. Getter materials that fail to meet these essential criteria will not be recommended in this evaluation. Ranking criteria are those 
which, while preferred, are not essential to getter function. Ranking criteria are invoked to evaluate getter materials that meet all of the screening criteria.

\section{Screening Criteria}

For the TRUPACT-II, a successful hydrogen getter must be able to maintain the $\mathrm{H}_{2}$ concentration in the ICV below $5 \%$ under these conditions:

1) temperatures from $-20^{\circ}$ to $170^{\circ} \mathrm{F}$

2) pressure up to 50 psig and brief exposure to vacuum (prior to shipment)

3) gas mixtures including VOCs, $\mathrm{H}_{2} \mathrm{~S}, \mathrm{CO}, \mathrm{H}_{2} \mathrm{O}, \mathrm{O}_{2}$, and anoxic conditions

In addition, the successful getter must withstand a radiological dose and must not cause the payload to surpass the TRUPACT-II weight limit. However, these factors are not expected to be a problem and thus are not included in the numbered list.

\section{$\underline{\text { Ranking Criteria }}$}

The following list of ranking criteria will be used to compare materials that satisfy the screening criteria above:

1) $\cos t$

2) material availability

3) state of development

4) recyclability

5) capacity for $\mathrm{H}_{2}$

6) weight

7) heat production

8) kinetics

9) simplicity of design

10) ease of handling/storage

The ability of the getter to be recycled could be a very attractive feature in that it could significantly reduce the cost of materials. However, if getters are placed within individual drums and disposed at WIPP, recyclability would not be an advantage. For perspective, recyclable getters should be evaluated both with and without the cost advantages of recycling.

\section{Description of Getter Materials}

There are several classes of materials that can be used to remove $\mathrm{H}_{2}$ from the TRUPACTII ICV. The following is a description of the major types of getters available. A more detailed discussion of some getters can be found elsewhere. ${ }^{8}$ Understanding how these 
materials function will give the reader a clearer picture of how each material type can be used to meet the design requirements.

\section{Group A - Unsaturated Organic with Hydrogenation Catalyst}

This type of getter uses an unsaturated organic molecule (containing $\mathrm{C}=\mathrm{C}$ or $\mathrm{C} \equiv \mathrm{C}$ bonds) and a hydrogenation catalyst to capture $\mathrm{H}_{2}$. The catalyst typically is from group VIII of the periodic table and is most commonly platinum, palladium, or rhodium. A prime example is the combination of 1,4-bis(phenylethyml)benzene (DEB), which has two $\mathrm{C} \equiv \mathrm{C}$ bonds, and a palladium-carbon catalyst. ${ }^{7}$ The selection of an organic molecule defines the materials' bulk properties such as melting point, density, and other physical characteristics. The catalyst is often coated on a carbon support then blended with the molten organic. As $\mathrm{H}_{2}$ diffuses into the mixture, the catalyst inserts the $\mathrm{H}_{2}$ across a carbon-carbon double or triple bond and releases heat associated with formation of the product. As will be discussed with recombination catalysts, these reactions are generally very fast and produce $\mathrm{H}_{2} \mathrm{O}$ when $\mathrm{O}_{2}$ is present. The heat associated with forming water $(58-68 \mathrm{kcal} / \mathrm{mol})$ is greater than that for formation of the saturated organic molecule (e.g., $35 \mathrm{kcal} / \mathrm{mol}$ for DEB). Poisons for this group of getters are essentially those that impact the catalyst's operation and are described in the next section.

\section{Group B - Recombination Catalysts}

This type of getter uses a catalytic surface to combine $\mathrm{H}_{2}$ and $\mathrm{O}_{2}$ into water. There are two different general types of recombination catalysts to be considered. The first type includes $\mathrm{Pt}, \mathrm{Pd}$, and $\mathrm{Rh},{ }^{10}$ which are often found in Group A mixtures. These materials have the advantage of working well at ambient temperatures. The heat of water formation can elevate the catalysts to a more efficient operating temperature even if ambient conditions are cool. The catalysts use $\mathrm{O}_{2}$ present in the gas mixture and may get very hot from reaction heat. Poisons include mineral acids, chlorinated solvents, sulfur compounds, phosphorus compounds, and carbon monoxide. ${ }^{10}$ Condensed water decreases the rate of reaction but does not prevent catalyst operation.

Recombination catalysts in the second group do not require $\mathrm{O}_{2}$ in the gas mixture but do require higher than ambient temperature conditions. The recombination reaction of $\mathrm{H}_{2}$ and $\mathrm{O}_{2}$ is exothermic and may generate sufficient heat to maintain the reaction rate. The materials used for this type catalyst are commonly $\mathrm{CuO}, \mathrm{ZnO}$ and $\mathrm{MnO}_{2}$, along with mixtures of these compounds. For example, a common mixture of $\mathrm{CuO}$ and $\mathrm{ZnO}$ with a silica binder is supplied in pellet form for use in industrial applications. Oxygen from the catalyst reacts with $\mathrm{H}_{2}$ to produce $\mathrm{H}_{2} \mathrm{O}$. When $\mathrm{O}_{2}$ is present in the gas, the catalyst returns to an oxide form. These catalysts are generally used in large beds and periodically regenerated. Materials that react with the metals to form new compounds that cannot be regenerated are considered poisons. The inexpensive nature of this type catalyst, however, supports a strategy of using more catalyst than required so that sufficient capacity remains even in the presence of poisons. The poisons for these catalysts include $\mathrm{Hg}$, sulfides, and halogens. 


\section{Group C-Metal Hydrides}

There are a very large number of metals and intermetallic compounds that form metal hydrides upon reaction with $\mathrm{H}_{2}$. A few specific examples include $\mathrm{Mg}, \mathrm{U}, \mathrm{ZrCo}, \mathrm{Mg}_{2} \mathrm{Ni}$, and LaNiAl. ${ }^{8,11}$ The hydriding reaction produces heat, and the direction of the reaction can be controlled by temperature. For example, hydrogen is absorbed by the metals at lower temperatures and released at higher temperatures. This behavior is illustrated for some common getter and storage materials by the van't Hoff diagram ${ }^{11}$ in Figure 5. The figure shows the expected $\mathrm{H}_{2}$ pressure achieved at different temperatures for various materials. Metal hydride materials with a high degree of reversibility are commonly called storage materials instead of getters. Metal hydride materials are susceptible to poisoning by contaminants and can easily be deactivated by absorption of other gases. However, those hydrides described as storage materials are less susceptible to poisoning, and $\mathrm{H}_{2}$ can be removed under more moderate conditions. A database of metal hydride materials that provides the basic data and references on about 800 hydride systems is available on the Internet at www.hydpark.ca.sandia.gov.

Classical use of metal hydrides includes heating as an activation step to prepare the materials for use. However, recent research has demonstrated preparation of metals capable of forming hydrides without the activation step. The proper selection of a metal hydride system for gettering applications requires information on the desired $\mathrm{H}_{2}$ pressure, working temperature range, required reaction kinetics, and possible poisons. Unlike materials that contain catalysts, metal hydrides are not expected to produce water if $\mathrm{O}_{2}$ is present.

\section{Group D - Composite Materials and Layered Products}

Recognizing the limitations in the above materials, particularly the susceptibility to poisons or other harmful gases, researchers have been developing and testing combinations of materials to overcome these limitations. Typically a gas separation technology is employed to protect the getter materials. In composites, getters are bonded to, combined, or blended with other materials. Often, polymers, silica, or other coatings are used to encapsulate the getter. This takes advantage of the very small, non-polar nature of $\mathrm{H}_{2}$ allowing it to penetrate to the getter while excluding larger, more polar molecules. An important example is the group of sol-gel based silica materials that form a porous glass.

A closely related type involves getters that are really getter composites. These "layered products" consist of a getter covered with one or more membranes. The combination of DEB and a Tedlar ${ }^{\circledast}$ membrane ${ }^{7}$ is an example being considered for use in the TRUPACTII. Another example of a layered product consists of a zirconium metal getter coated with a proprietary metal coating. ${ }^{12}$ Application of appropriate membrane layers and/or composite combinations is an important design requirement for a necessarily robust getter system for the TRUPACT-II. 


\section{Impact of Operating Parameters on Getter Design}

From the list of regulatory conditions inside the TRUPACT-II (mentioned under Safety in the Evaluation Criteria section above), it is possible to identify five operating parameters important in the selection and design of a getter device (Table 1). Though pressure is an operating parameter that can vary, the limits imposed by the SARP should prevent pressure from adversely affecting getter performance. Consideration of the impact of each of these parameters on the function and design of the getter device is essential in evaluating materials for use as getters in the TRUPACT-II ICV.

Table 1 - Impact of Operating Parameters on Getter Function and Design

\begin{tabular}{|l|l|}
\hline Parameter & \multicolumn{1}{c|}{ Impact on Function/Design } \\
\hline Thermal & - Reaction kinetics for catalysts \\
& - Kinetics and extent of absorption into metal hydrides \\
& - Heat of reaction reduces allowed heat load of payload \\
\hline Gas Mixture & - Getter apparatus must function in air-hydrogen mixtures \\
& - Water produced with use of hydrogenation catalysts \\
& - Sufficient $\mathrm{O}_{2}$ is need for recombination catalysts to function \\
\hline Poisons & - Some gases and vapors reduce reaction kinetics of getter material \\
& - Design must anticipate presence of poisons and compensate \\
\hline $\mathrm{H}_{2}$ Generation & - Determines the quantity of getter material required \\
Rate & - Reaction rate determines required cooling \\
& - For some getters, water formation is proportional to $\mathrm{H}_{2}$ gettering \\
\hline Waste Type & - Determines the type and relative quantities of gases generated \\
& - Age of waste affects generation rates and consumption of $\mathrm{O}_{2}$ \\
& - Determines type and quantity of poisons present \\
\hline
\end{tabular}

Quantifying these parameters for each shipment of waste in the TRUPACT-II could be based on measurements and on historical data for each of the loaded storage drums. This would allow wastes to be grouped and a getter material to be selected for each waste group. However, using the bounding limits established by the TRUPACT-II SARP provides a more versatile getter apparatus and is the approach recommended by this review.

The five operating parameters presented in Table 1 are foundational to the selection of a getter material for design of the TRUPACT-II getter system. A discussion of each parameter's impact on material selection is presented below. Four parameters, 1) Thermal, 2) Gas Mixture, 3) Poisons, and 4) $\mathrm{H}_{2}$ Generation Rate, will be discussed individually, with effects of 5) Waste Type included in each of these sections. 


\section{Thermal}

- The allowed temperature range within the TRUPACT-II, as defined by the TRUPACT-II SARP, is $-20^{\circ}$ to $170^{\circ} \mathrm{F}$. It is expected that a TRUPACT-II with $80 \mathrm{~g}$ of $\mathrm{Pu}-238$ packaged during a South Carolina summer and shipped to WIPP will never see freezing temperatures. So, it is possible to establish additional controls to maintain the ICV within a narrower range of temperature; however, this institutes additional operating constraints that should be avoided at this point in material selection.

- The total heat load permitted within the TRUPACT-II is 40 watts. Since each getter uses a chemical or catalytic reaction that is exothermic, heat is liberated based on the rate of reaction. Recombination of $\mathrm{H}_{2}$ and $\mathrm{O}_{2}$ produces the greatest amount of heat, followed by hydrogenation of organic materials. Absorption of $\mathrm{H}_{2}$ to form metal hydrides produces about half the heat generated by recombination into water.

\section{Gas Mixture}

- Two of the three basic getter materials (composites not included) function best in an environment without $\mathrm{O}_{2}$ present. Assuring that no $\mathrm{O}_{2}$ is present is difficult to achieve, since the TRUPACT- $\Pi$ is not packed with an inert atmosphere and radiolysis of contained moisture liberates $\mathrm{O}_{2}$.

- The ICV void volume and the concentration of $\mathrm{O}_{2}$ in air define the starting quantity of $\mathrm{O}_{2}$. The minimum ICV gas volume is established by the TRUPACT-II SARP for $\mathrm{H}_{2}$ calculations and is conservative - at less than $40 \%$ of the total volume - because drums are assumed to have no void space. Some waste forms are known to consume $\mathrm{O}_{2}$, a fact that complicates the use of hydrogenation catalysts for recombination, because the availability of $\mathrm{O}_{2}$ must be evaluated for each case.

- The quantity of water generated in the presence of recombination catalysts must be prevented from inhibiting catalyst function or blocking gas movement under freezing conditions.

\section{Poisons}

- Some waste forms decompose to produce poisons that have a detrimental effect on the function of the various getter materials. The effects on getter operation from gas and vapor poisons are expected to worsen as their concentration increases. These effects need to be evaluated thoroughly to assure safe function, reliability, and NRC acceptance of the getter apparatus. The expectation that poisons at some level affect all getters is the driving force to develop composite getter materials. 


\section{$\underline{\mathrm{H}}_{2}$ Production Rates}

- $\mathrm{H}_{2}$ generation rates will vary with waste type and radiological decay energy. The amount of $\mathrm{H}_{2}$ produced can be bounded by looking at 40 watts of decay energy and a waste with high $\mathrm{G}$-values (molecules $\mathrm{H}_{2}$ produced per $100 \mathrm{eV}$ dose). The TRUPACT-II SARP has calculated a wattage limit for each waste type using the Gvalue and minimum ICV volume to produce a $\mathrm{H}_{2}$ concentration of $5 \%$ in the 60 -day shipping window. Using this data, a calculated $\mathrm{H}_{2}$ generation rate for waste forms with large G-values is presented in the Appendix.

- The quantity of getter material required to capture all $\mathrm{H}_{2}$ generated becomes a primary. input in calculation of the getter system cost and subsequent calculation of heat generated, water produced and device size.

\section{Evaluation of Current and Developing Technologies}

Previously, a list of screening criteria was outlined which must be met in order for a getter material to function effectively under conditions defined by the TRUPACT-II SARP. Each of the major categories of getter materials described above is evaluated against these screening criteria to determine their suitability for use in the TRUPACT-II.

The first screening criterion required the getter material to function effectively at temperatures from $-20^{\circ}$ to $170^{\circ} \mathrm{F}$. In each group of getters there are materials that can function within this temperature range. However, some organics melt at the high temperature, and many recombination catalysts stop functioning effectively at the low temperature. In addition, most getters can function in the pressure range ( $<50 \mathrm{psig})$ specified in the SARP.

The biggest problem, by far, is the effect of poisons on getter function. The gettering effectiveness of three getter categories - unsaturated organics, recombination catalysts, and metal hydrides-is inhibited by one or more poisons expected to be present in the TRUPACT-II ICV. Also, many recombination catalysts require the presence of oxygen to remove $\mathrm{H}_{2}$. Fortunately, some composite/layered materials have the distinct advantage of overcoming the detrimental affects of poisons. These materials meet all the screening criteria and, therefore, are worthy of further consideration for use in the TRUPACT-II. A simplified summary of the performance of the major getter types relative to the screening criteria of Table 1 is given in Table 2.

The next section discusses several ways that poisons can be mitigated. After that, specific getters that meet the screening criteria are evaluated relative to the list of ranking criteria. 
Table 2. Evaluation of Getter Materials vs. Screening Criteria

\begin{tabular}{|l|c|c|c|c|}
\hline $\begin{array}{c}\text { Screening } \\
\text { Criteria }\end{array}$ & $\begin{array}{c}\text { Unsaturated } \\
\text { Organic } \\
\text { Catalyst }\end{array}$ & $\begin{array}{c}\text { Recombination } \\
\text { Catalysts }\end{array}$ & $\begin{array}{c}\text { Metal } \\
\text { Hydrides }\end{array}$ & $\begin{array}{c}\text { Composite/Layered } \\
\text { Materials }\end{array}$ \\
\hline $\begin{array}{c}\text { Functions at: } \\
-20^{\circ} \mathrm{F}\end{array}$ & Yes & No & Yes & Yes \\
$170^{\circ} \mathrm{F}$ & Yes & Yes & Yes & Yes \\
\hline $\begin{array}{l}\text { Functions at } \\
\text { Pressures up to }\end{array}$ & & & Yes & Yes \\
50 psig & Yes & Yes & & \\
\hline Functions in gas & & & & \\
mixtures & & & No & Yes \\
containing: & No & No & Yes & Yes \\
Poisons & Yes & Yes & Yes & Yes \\
$\mathrm{H}_{2} \mathrm{O}$ & Yes & Yes & Yes & Yes \\
$\mathrm{O}_{2}$ & Yes & Some & & \\
$\mathrm{No}_{2}$ & & &
\end{tabular}

\section{Dealing with Gas and Vapor Poisons}

$\mathrm{Mroz}^{7}$ has identified six classes of compounds that getters are likely to encounter when operating in the TRUPACT-II ICV. These include:

\begin{tabular}{|l|l|}
\hline Classification & Examples \\
\hline inorganic gases & $\mathrm{H}_{2} \mathrm{~S}, \mathrm{HCl}, \mathrm{CO}$ \\
\hline halogenated olefins & $\mathrm{TCE}, \mathrm{TCA}$ \\
\hline halogenated alkanes & $\mathrm{CCl}_{4}$ \\
\hline alcohols & $\mathrm{Methanol}$ \\
\hline ketones & Acetone \\
\hline aromatics & Toluene \\
\hline
\end{tabular}

Wastes from different DOE sites are likely to have unique characteristics based on the processes that contributed to the waste stream. Because each drum headspace will be analyzed and vented before shipping, drums could be matched in a manner to allow maintaining a volatile organic carbon (VOC) concentration limit. One alternative to testing actual conditions is to test limiting concentrations. For example, the TRUPACTII SARP imposes a $500 \mathrm{ppm}$ limit for flammable VOCs, which could serve as one basis for qualifying a getter material. Nonflammable VOCs should also be tested as potential poisons at their respective concentration limits (listed in the Appendix).

While various reports have shown $\mathrm{O}_{2}$ depletion over long periods of time (e.g., 1 year) little $\mathrm{O}_{2}$ loss is expected in a 60-day duration. One notable exception is a sludge waste at Rocky Flats, which showed loss of all $\mathrm{O}_{2}$ in less than 18 days. This change was 
attributed to a chemical reaction and not radiation effects. The $\mathrm{O}_{2}$ in a drum containing sludge could be consumed by either a corrosive reaction (i.e. rusting a carbon steel drum) or growth of biological organisms.

There are two good alternatives for protecting getter materials from potential poisons in the TRUPACT-II ICV. These include 1) composite materials and 2) layered products. The composite materials prevent permeation of the poison to the getter material by using a support matrix. In addition, composite getters provide a large surface for diffusion of $\mathrm{H}_{2}$ to the getter material to maintain rapid getter kinetics. One good example of a composite getter material is a sol-gel metal hydride patented by SRS. The metal hydride is suspended in a porous glass matrix that allows small $\mathrm{H}_{2}$ molecules to penetrate but keeps out larger poison gases like $\mathrm{CO}$ and $\mathrm{O}_{2}$. Another good example is a DEB composite with an alternative support. Typically DEB is formulated with silicone rubber to allow formation of shaped objects and pellets that are easily handled. The silicone could potentially be substituted with Kapton ${ }^{\circledR}$ or another polyimide that allows preferential diffusion of $\mathrm{H}_{2}$ over poisons. The feasibility of this substitution has been discussed with Schicker ${ }^{13}$ at the Kansas City Plant.

The second good alternative for protecting getter materials from poisons is the use of layered products. In this case, the total gas passes through multiple layers of absorbents or membranes to remove problem components, and the getter material is located in the center. Consider the following sketch as a conceptual design.

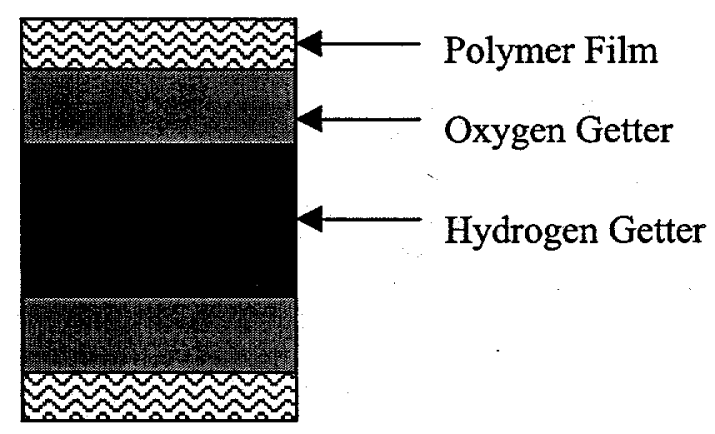

The polymer film protects the hydrogen and oxygen getters from poisons. If, for example, $\mathrm{DEB}$ is combined with an $\mathrm{O}_{2}$ getter like $\mathrm{MnO}$, and the getters are protected from poisons by a polymer film, the DEB could function without producing $\mathrm{H}_{2} \mathrm{O}$. Because polymer films change permeability as a function of temperature, ${ }^{14}$ an evaluation of this concept over the TRUPACT-II temperature range is needed. Nevertheless, layered products are one option for addressing the TRUPACT-II hydrogen accumulation problem.

In the design of layered products, one of the biggest challenges is to provide sufficient surface area, which if insufficient, can slow the overall absorption rate. Rolled products and other designs could be used to increase the surface area, yet remain difficult to implement in terms of getter system design. 
Another alternative is a composite that uses a layered arrangement of materials. The Pacific Northwest National Laboratory (PNNL) composite ${ }^{12}$ consists of a zirconium (Zr) metal getter covered with a proprietary metal coating. The device shows an absorption rate greater than $1 \mathrm{~mole}_{2} / \mathrm{day} / \mathrm{kg}$ in a vacuum or inert gas but is rated at 1-2 millimole $\mathrm{H}_{2} /$ day $/ \mathrm{kg}$ in air. The metallic coating prevents oxidation of the $\mathrm{Zr}$ but is unable to sustain rapid $\mathrm{H}_{2}$ removal in air. Once the air is removed, the $\mathrm{Zr}$ begins to function again as the $\mathrm{H}_{2}$ atmosphere reduces the surface coating. Without further improvements, this system is not a practical option for the TRUPACT-I, because its kinetics in air would require about $500 \mathrm{~kg}$ to meet the maximum $\mathrm{H}_{2}$ generation rate specified in the SARP. (See Attachment 1 of the Appendix for a calculation of getter requirements.)

In addition to the use of composite and layered products to filter out poisons, other design concepts that can be employed to mitigate the effects of some poisons include:

- Chemical Reactions:

$$
\begin{aligned}
& \mathrm{O}_{2}+2 \mathrm{LiH} \rightarrow 2 \mathrm{LiOH} \\
& \mathrm{MgH}_{2}+\mathrm{O}_{2} \rightarrow \mathrm{Mg}(\mathrm{OH})_{2} \\
& \mathrm{MgH}_{2}+2 \mathrm{H}_{2} \mathrm{O} \rightarrow \mathrm{Mg}(\mathrm{OH})_{2}+2 \mathrm{H}_{2} \\
& \mathrm{CaCl}_{2}+\mathrm{H}_{2} \mathrm{O} \rightarrow \mathrm{CaCl}_{2} \cdot \mathrm{H}_{2} \mathrm{O}
\end{aligned}
$$

- Provision of excess getter to react with poisons and maintain reaction rate:
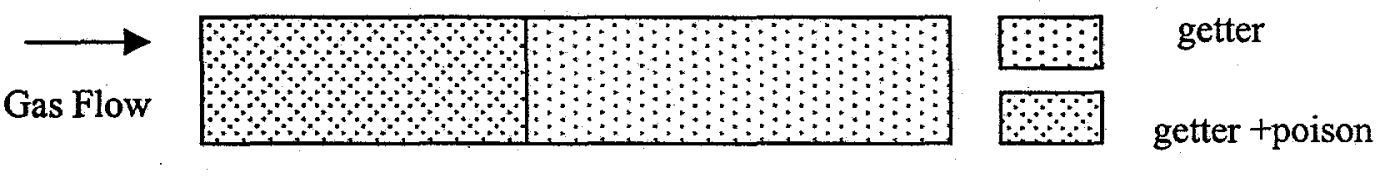

- Combination of gas separation membrane and excess getter

- Combinations of getter materials:

- Copper $(\mathrm{Cu})$ metal + Pd catalyst - uses the heat released from catalyst operation to heat-up $\mathrm{Cu}$. $\mathrm{Cu}$ then reacts with many of the gases that poison Pd catalysts.

- $\mathrm{Cu}$ metal $+\mathrm{Pd}$ catalyst $+\mathrm{CaCl}_{2}$ - as above, but with a desiccant to remove water produced by recombination catalyst.

- Polyimide film + Pd catalyst - uses the polyimide film to reduce the quantity of poisons reaching the catalyst surface

The point of this discussion is to identify the large number of possible combinations of materials and engineering options that are available for solving the TRUPACT-II $\mathrm{H}_{2}$ concentration problem. However, two options have emerged as promising candidates. They are discussed in more detail in the following section.

\section{Evaluation of Composite Systems}

The two most promising materials being considered are described below and discussed in terms of the ranking criteria established earlier in this document for the TRUPACT-II. 
DEB + membrane. As part of the US weapons program, DEB has been thoroughly evaluated for use in transportation of tritium gas. DEB can be combined with membrane materials as a layered product or as a composite to minimize the effect of poisons on the hydrogenation catalyst. As a composite, DEB has been incorporated into a shaped polyethylene, a urethane adhesive, and a castable RTV silicone. More recently, its use is being investigated as a getter combined with a membrane that inhibits chlorinated VOCs.

Sol-Gel Metal Hydride (SGMH). This material has received little attention by the MWFA but has demonstrated some of the most desirable properties required for service within the TRUPACT-II. SGMH was invented in the early 90 's and tested for recovery of $\mathrm{H}_{2}$ from mixed gas streams associated with operation of an oil refinery. SGMH has been patented and demonstrated for compositions of LaNiAl. ${ }^{15}$ Subsequent testing shows that the metal hydride is protected from $\mathrm{CO}$ and, to a lesser extent, from $\mathrm{H}_{2} \mathrm{~S} .{ }^{16}$

Three closely related ranking criteria from the list given in Table 1 are cost, availability of materials, and state of development. All three are important considerations in the selection of a getter for any application. Both DEB and SGMH have only one supplier at this time. DEB is currently available at approximately $\$ 3$ per gram in a granulated form. Forms requiring more labor to produce are more costly. ${ }^{13}$ However, to be effective in the TRUPACT-II, DEB must be engineered in a form which will minimize the effect of poison gases on the hydrogenation catalyst. The cost of development for such a DEB material is not known, but DEB is expected to be available in whatever form necessary. SGMH compounds are not yet available "off the shelf." However, funding is in place to make and test promising combinations this year. Both materials have been patented, though a patent number has not yet been issued for SGMH. Though DEB has been developed, used and tested to a greater extent, the combination of DEB and an effective poison protector has not yet been demonstrated.

Since both of these materials are still in the development stage, it is somewhat difficult to compare them on a cost basis at this time. However, it is probable that the financial savings achieved by successful implementation of a $\mathrm{H}_{2}$ getter device will offset the cost of development for either system. Since a recyclable getter is probably most desirable, SGMH has a clear advantage over a DEB composite or layered product, because the reaction of DEB with $\mathrm{H}_{2}$ is irreversible.

The capacity of the getter material for $\mathrm{H}_{2}$ is also an important consideration. Pure DEB has a theoretical $\mathrm{H}_{2}$ capacity of $14 \mathrm{mmol} \mathrm{H}_{2}$ per gram of DEB $\left(71 \mathrm{~g} \mathrm{DEB}\right.$ per $\left.\mathrm{mol} \mathrm{H}_{2}\right)$ if completely hydrogenated. However, the functional $\mathrm{H}_{2}$ capacity of a DEB composite or layered product will necessarily be less than this, since only a portion of the device will consume $\mathrm{H}_{2}$. Similarly, the $\mathrm{H}_{2}$ capacity of SGMH cannot be stated simply, because it depends on several variables. First, it depends on the choice of metal or intermetallic hydride system. For example, the $\mathrm{LaNi}_{4.25} \mathrm{Al}_{0.75}$ system has a $\mathrm{H}_{2}$ capacity of $5.6 \mathrm{mmol} \mathrm{H}_{2}$ per gram of LaNiAl (179 $\mathrm{g} \mathrm{LaNiAl}$ per mol $\mathrm{H}_{2}$ ). Second, when prepared as an SGMH, the weight percent of metal in the sol-gel composite could range from $15 \%$ to $70 \%$, depending on the desired properties. The degree to which dilution is required will 
determine the $\mathrm{H}_{2}$ capacity of SGMH on a mass basis. Thus, it appears that the weight of getter material required to getter a given amount of $\mathrm{H}_{2}$ will be less for DEB than SGMH, but this will depend on the properties of the actual device employed. In either case, the maximum amount of getter material required is expected to be about $100 \mathrm{~kg}$, which would have little impact on the total weight of the TRUPACT-II.

The amount of heat produced by the two materials is similar. The heat of reaction is estimated to be about $-35 \mathrm{kcal} / \mathrm{mol} \mathrm{H}_{2}$ for DEB and about $-30 \mathrm{kcal} / \mathrm{mol} \mathrm{H}_{2}$ for $\mathrm{SGMH}$. However, the issue is more complicated when the performance of DEB in air is considered. With oxygen present, as will most likely be the case, the palladium catalyst included in the DEB formulation causes a preferential formation of water instead of the hydrogenation of DEB. As a result, much more heat is generated-58 to $68 \mathrm{kcal} / \mathrm{mol} \mathrm{H}_{2}$. Therefore, if the DEB formulation is converting hydrogen and oxygen into water (or water vapor), it produces about twice as much heat as SGMH. Even for water formation, the amount of heat generated by getter materials should be less than $10 \%$ of the allowed heat load of the TRUPACT-II. See Attachment 2 of the Appendix for a detailed calculation.

The reaction of DEB with $\mathrm{H}_{2}$ is very rapid and increases with increasing temperature. The absorption of $\mathrm{H}_{2}$ by SGMH, while less rapid than that of DEB, is still reasonably fast relative to the expected rate of $\mathrm{H}_{2}$ generation. Since both materials are still under development, the factor of design simplicity remains in question. Nevertheless, the solgel matrix has been shown to protect metal hydrides from some classic poisons. ${ }^{15}$ Hence, SGMH would not require an outer protective membrane, making design and development easier than for DEB. Table 3 provides a comparison of the DEB and SGMH systems in terms of the ranking criteria.

Table 3. Evaluation of DEB and SGMH Getter Systems vs. Ranking Criteria

\begin{tabular}{|c|c|c|}
\hline RANKING CRITERIA & $\begin{array}{c}\text { DEB COMPOSITE/ } \\
\text { LAYERED PRODUCT }\end{array}$ & SGMH \\
\hline Cost & ? & $?$ \\
\hline Availability & Small scale? & Small scale \\
\hline State of development & In progress & In progress \\
\hline Recyclability & No & Yes \\
\hline $\mathrm{H}_{2}$ capacity & $<14 \mathrm{~mol} / \mathrm{kg}$ & $<5.6 \mathrm{~mol} / \mathrm{kg}$ \\
\hline Relative weight & 1 & $\sim 2-2.5$ \\
\hline Heat generation & $\begin{array}{c}\sim 68 \mathrm{kcal} / \mathrm{mol} \mathrm{H}_{2} \text { in } \operatorname{Air}\left(\mathrm{H}_{2} \mathrm{O}\right. \\
\text { produced) } \\
\sim 35 \mathrm{kcal} / \mathrm{mol} \mathrm{H}_{2} \text { w } / \mathrm{o} \text { Air }\end{array}$ & $\sim 30 \mathrm{kcal} / \mathrm{mol} \mathrm{H}_{2}$ \\
\hline Kinetics & Very good & Good \\
\hline Design simplicity & $?$ & $?$ \\
\hline Ease of handling and storage & Stable in air & Stable in air \\
\hline
\end{tabular}


Strengths of the DEB system include high capacity, rapid kinetics, irreversibility (if recycling is not desired), and apparent availability. Mroz at $\mathrm{LANL}^{7}$ has done extensive testing of DEB for application in the TRUPACT-II ICV. In comparison with metal hydrides, the DEB system weaknesses include:

1) Formation of $\mathrm{H}_{2} \mathrm{O}$ with $\mathrm{O}_{2}$ present

2) Poisoning of $\mathrm{Pd}$ by gaseous species

3) High relative cost for non-reusable units

Mroz has reported ${ }^{17}$ that he is working with membranes to prevent poisoning by halogenated organic species. Also yet to be demonstrated is the function of DEB at low temperatures. Encapsulating DEB in Kapton ${ }^{\circledR}$ may help minimize the problems with poisons and offer better kinetics than some polymer membranes.

In the case of SGMH, SRTC has recently demonstrated application of the sol-gel encapsulation technique to metal hydrides other than LaNiAl. The use of SGMH instead of the unprotected metal hydride offers several advantages including:

1) Reduced or eliminated impact of poisons

2) Easier handling (no reactions with air)

3) Minimal decrepitation

4) No impact on metal hydride kinetics

Compared to DEB, an advantage of SGMH is the ability to regenerate and reuse the getter. In addition, SGMH is not expected to produce water, which results in a lower heat of reaction with $\mathrm{H}_{2}$ in the presence of $\mathrm{O}_{2}$. However, DEB may offer advantages in terms of material weight and maturity of its test program.

Extensive testing has been done on $\mathrm{ZrCo}$ and $\mathrm{LaNiAl}$ for the processing and storage of $\mathrm{H}_{2}$ isotopes. These tests were done without the benefit of SGMH composites; however, available material characterizations show that these materials in an SGMH matrix are good candidates for removing $\mathrm{H}_{2}$ from the TRUPACT-II ICV.

Uncertainties that exist and will be worked out by SRTC development efforts in the coming months include:

1) Evaluation of manufacturing costs and scale-up of SGMH production;

2) Composite testing of candidate materials $\left(\mathrm{ZrCo}, \mathrm{NdCo}_{3}, \mathrm{Mg}_{2} \mathrm{Ni}\right)$;

3) Test kinetics and capacity at temperature extremes required by the SARP.

4) Examine the effect of various potential poisons on SGMH getter function. 


\section{Conclusions}

Every getter material reviewed has some inherent limitations for use in transportation of TRU material. The biggest challenge for getter applications within the TRUPACT-II is mitigation of poisons, which can be addressed by using a composite getter material like sol-gel metal hydride (SGMH). SGMH allows designers to take advantage of the full range of metal hydride compounds. In addition, SGMH has cost advantages over other composite systems, since it can be recycled and its metal components cost less than DEB.

Development efforts must start by demonstrating the effectiveness of a low-pressure SGMH system. As current work at LANL, PNNL, SRS, and elsewhere is completed, one or two getter system options should be selected for testing in a pilot-scale TRUPACT-II mock-up. Scaled testing is necessary to develop specific understanding of the effects of getter operation within the range of operating conditions imposed by the TRUPACT-II SARP. Also, scaled tests will allow multiple iterations in improvement of the getter system design. NRC acceptance of a getter system will require rigorous testing that should be initiated following the pilot-scale evaluation.

\section{Acknowledgements}

The authors gratefully acknowledge helpful discussions with Kit Heung and Kurt Houghtaling in the preparation of this document. 


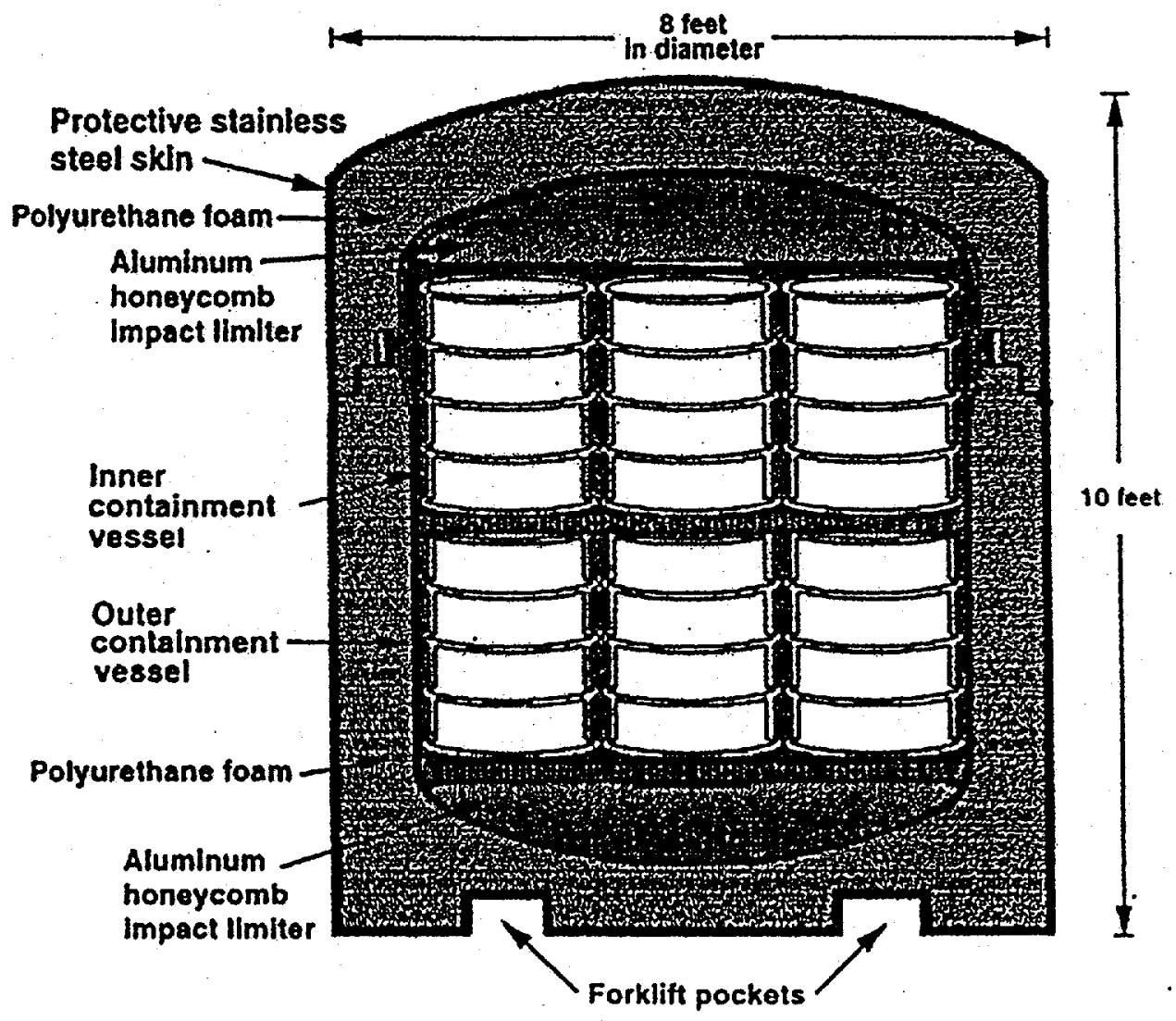

Figure 1. Side view cross-section of TRUPACT-II containing drums. ${ }^{18}$ 


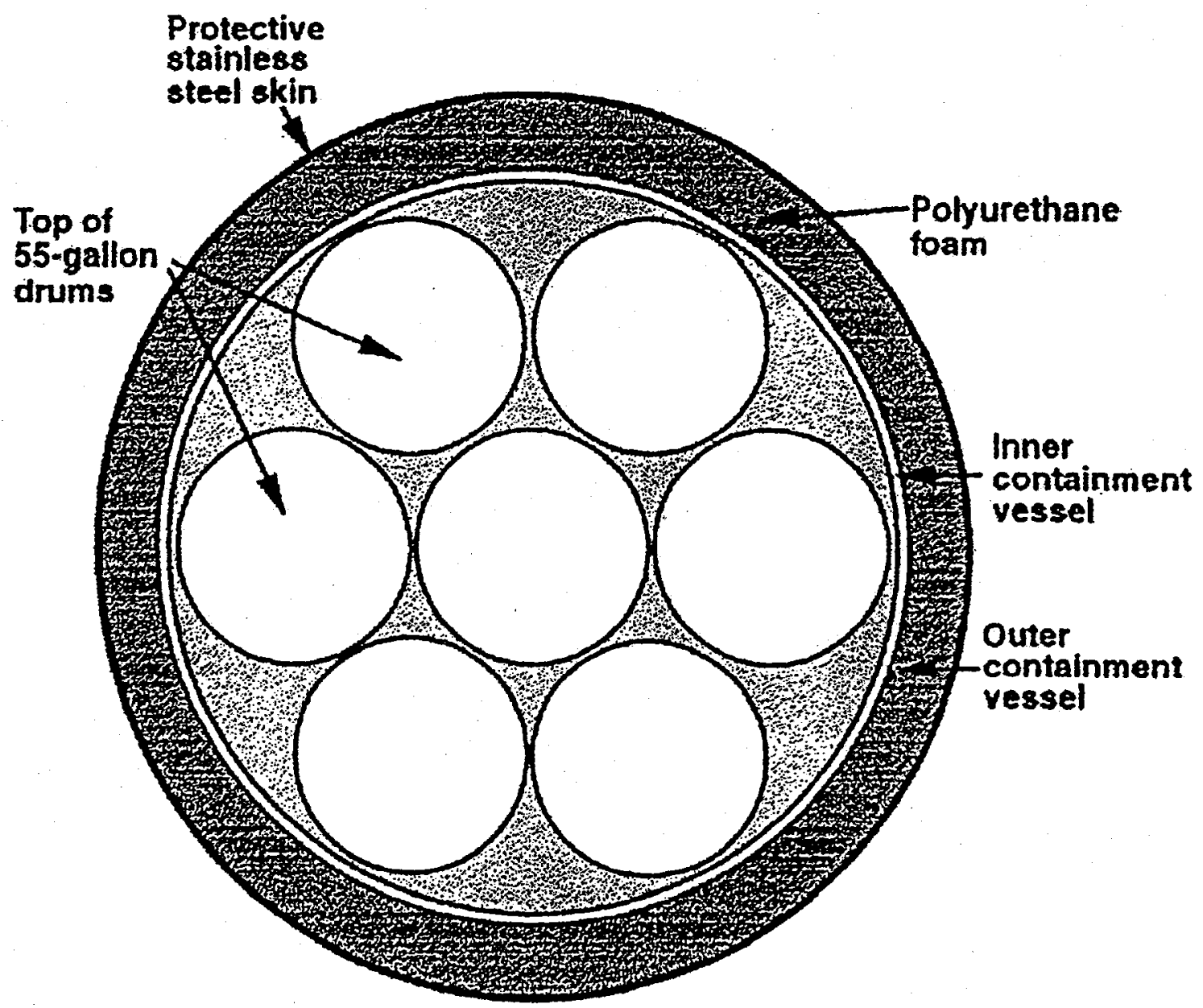

Figure 2. Top view cross-section of TRUPACT-II containing drums. ${ }^{18}$ 


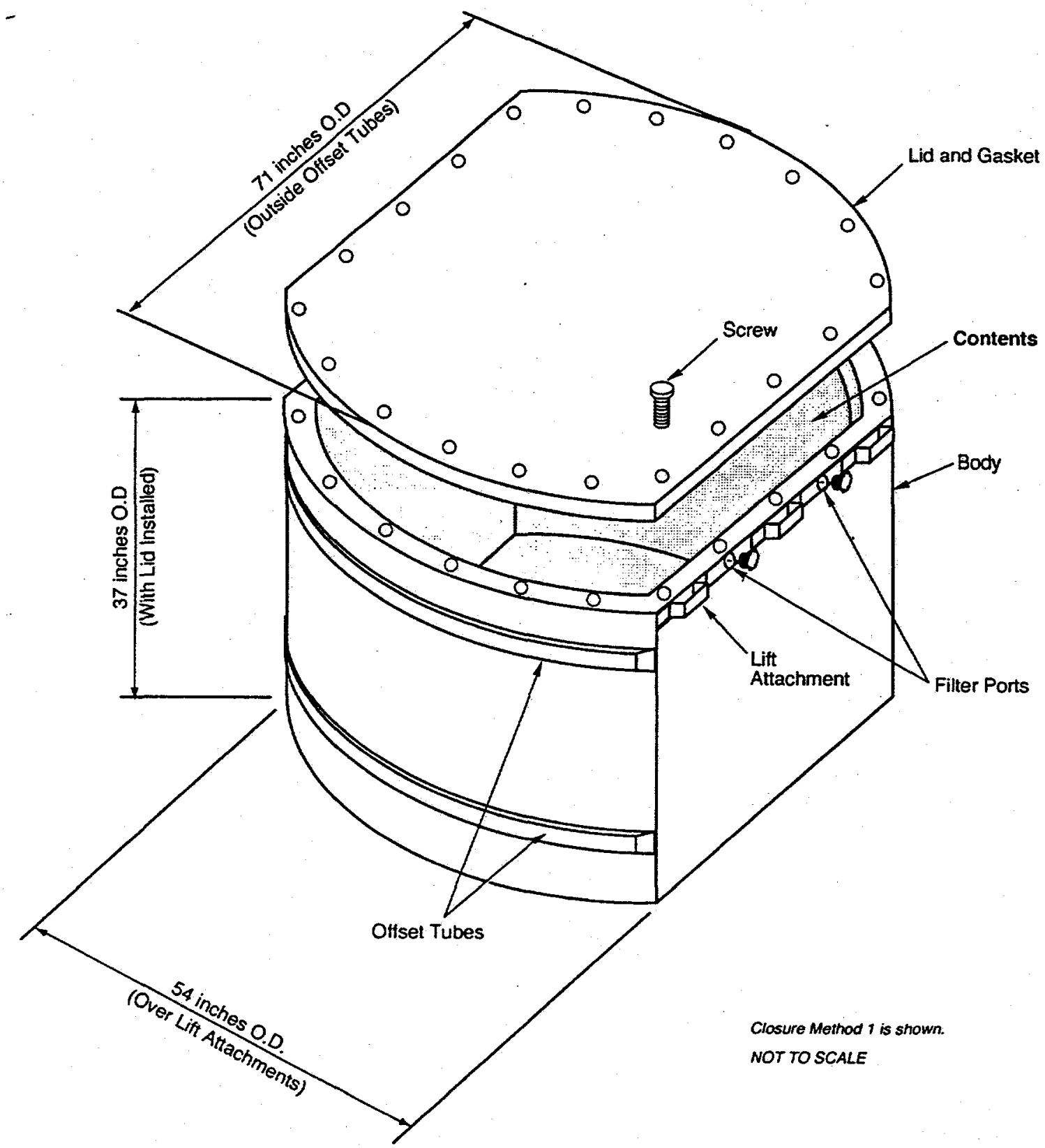

Figure 3. Standard Waste Box. ${ }^{1}$ 

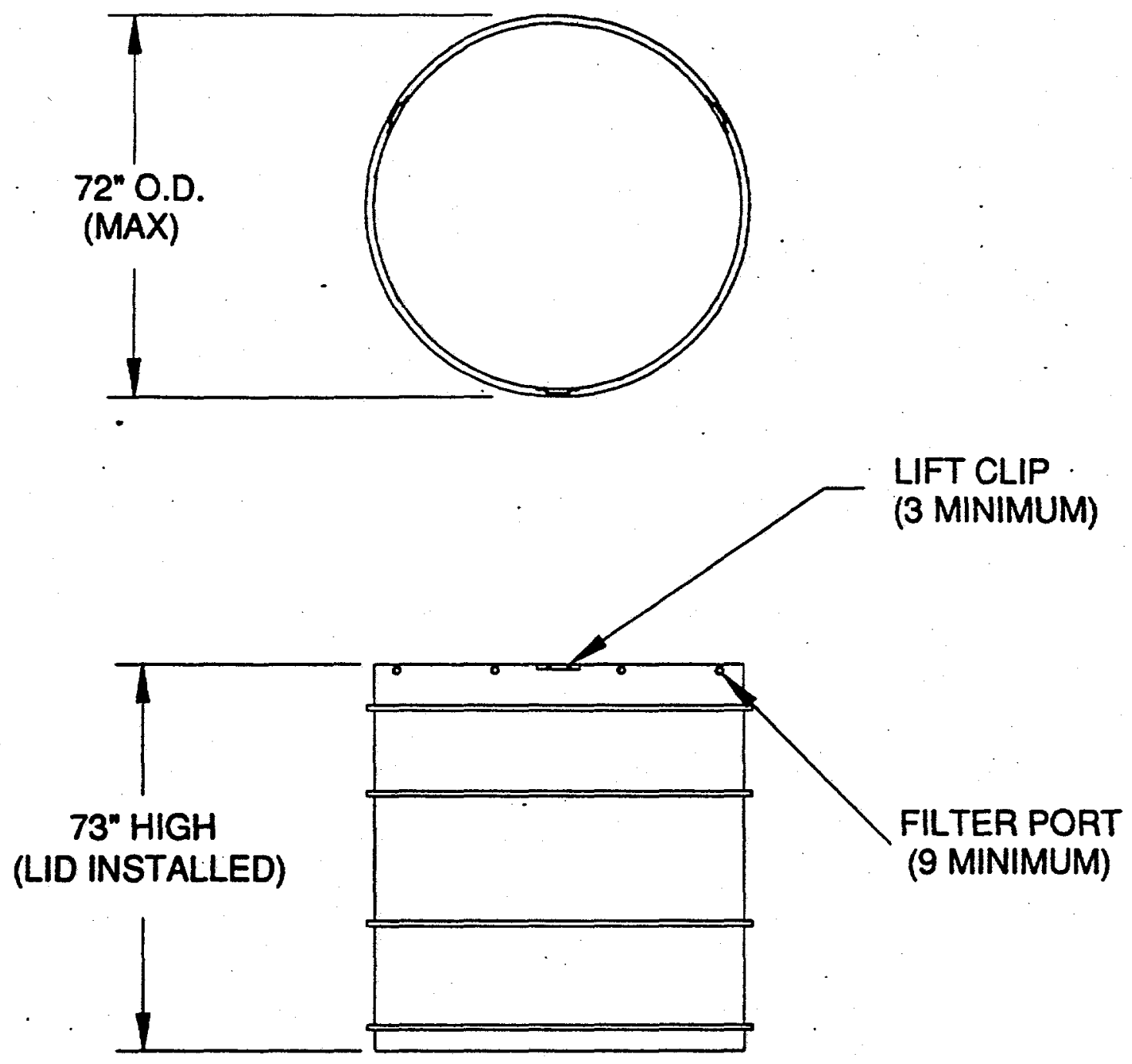

Figure 4. Ten-drum overpack: top and side views. ${ }^{1}$. 


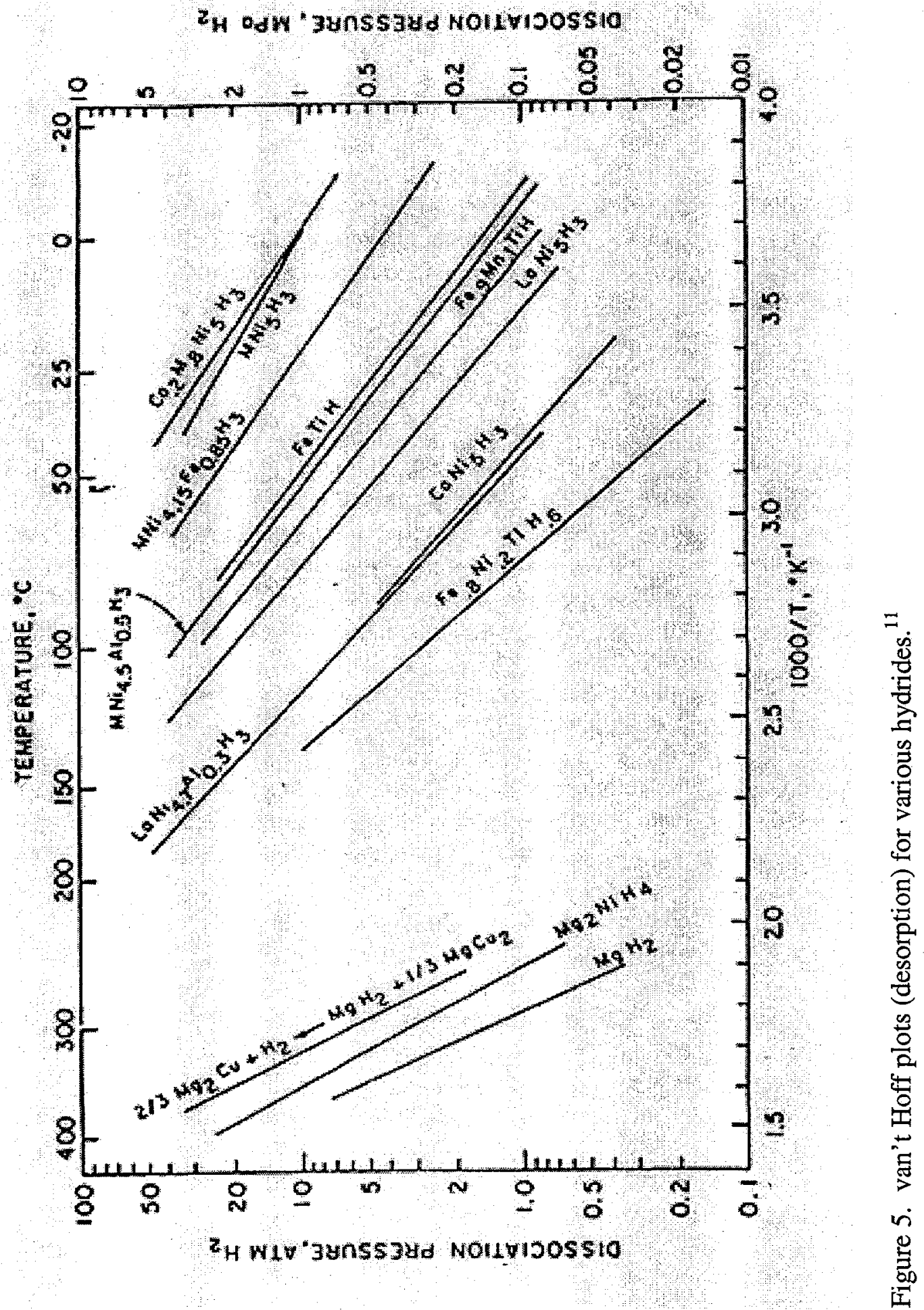


WSRC-TR-99-00160

\section{Appendix}

\section{Design Criteria for the TRUPACT-II which Influence Hydrogen Getter Design}

\section{Summary}

In this study, the design requirements for using hydrogen getters in the TRUPACT-II are identified. The TRUPACT-II SARP was the main source of information, though additional references are included. A successful hydrogen getter must be able to maintain the concentration of $\mathrm{H}_{2}$ below $5 \%$ inside the TRUPACT-II. It must function under these conditions:

1) internal pressures up to $50 \mathrm{psig}$;

2) temperatures from -20 to $170^{\circ} \mathrm{F}$;

3) a wide variety of TRU-contaminated waste types;

4) headspace gas and vapor compositions containing up to $500 \mathrm{ppm}$ flammable volatile organic compounds (VOCs), higher levels of nonflammable VOCs, and potential poisons such as sulfides, $\mathrm{CO}$, etc.;

5) presence or absence of oxygen;

6) briefly applied vacuum conditions (to test TRUPACT-II seals); and

7) presence of water vapor (which may condense or freeze onto the getter surface).

In addition, a successful getter system must withstand some level of radiation dose, fit well physically within the TRUPACT-II, and meet the TRUPACT-II weight limit (not anticipated to be a problem). An additional conclusion is that a heavy getter arrangement must be placed in the bottom half of the TRUPACT-II. A getter system that meets these criteria will satisfy the presently-stated concerns of the Nuclear Regulatory Commision ${ }^{8}$ for use in the TRUPACT-II.

\section{Motivation}

Across the Department of Energy (DOE) complex, thousands of drums and other waste forms are being stored and await shipment to the Waste Isolation Pilot Plant (WIPP) in Carlsbad, New Mexico for long-term disposal. Much of the waste earmarked for disposal at WIPP contains transuranic material, and will be shipped there in the Transuranic Package Transporter-II (TRUPACT-II). Under current regulations, however, many drums cannot be shipped to WIPP because their contents exceed the radioactive wattage limits set forth in the Safety Analysis Report for the TRUPACT-II Shipping Package' (i.e., the TRUPACT-II SARP). These wattage limits were conservatively set to prevent the buildup of a flammable amount of hydrogen gas. At the Savannah River Site (SRS), roughly 7,000 out of 11,000 drums containing plutonium cannot be shipped to WIPP because they exceed the wattage or decay heat limits. ${ }^{6}$ The proposed corrective 
methods for these drums are to sort/segregate/repackage and to mitigate gas generation. In addition, the Matrix Depletion Program at Los Alamos National Laboratory (LANL) is conducting experiments aimed at increasing the TRUPACT-II wattage limits. Even after such increases, SRS would still need corrective action for about half of its drums.

One avenue being explored to resolve the issue of radiolytic hydrogen generation inside the TRUPACT-II is the use of either hydrogen getters or hydrogen storage devices. Getters are materials which chemically combine with gaseous hydrogen, thereby removing hydrogen from the vapor state. This is typically an irreversible chemical reaction. Hydrogen storage devices, which are sometimes called getters, chemically combine with gaseous hydrogen, but the reaction in this case is reversible. Certain conditions, such as low pressure and/or high temperature, can be used to "pull" the hydrogen from the storage device. The storage material would then be ready to chemically combine with hydrogen again.

Many hydrogen getters and storage devices, referred to hereafter as getters, are available commercially. Engineering criteria are needed for the use of getters within the TRUPACT-II to enable thorough and objective evaluation. This paper provides those criteria, using many references to the TRUPACT-II SARP. A second paper will discuss the merits and shortcomings of various commercially available getters and of getters that are still under development.

\section{The TRUPACT-II}

Before moving on, it is useful to consider the structure of the TRUPACT-II, which has already been qualified as a type $B$ shipping package. To this end, it has passed numerous tests, including a free-drop test (from 30 feet), a puncture test, a thermal (30minute fire) test, and immersion tests. In all cases, the TRUPACT-II was shown to prevent the release of radioactive material from its payload.

As shown in Figure 1, the TRUPACT-II provides double containment for its payload, which is housed within the Inner Containment Vessel (ICV). The annulus region between the ICV and the Outer Containment Vessel (OCV) is essentially filled with polyurethane foam, which provides impact protection as well as thermal insulation. Both ICV and OCV are made of stainless steel. Aluminum honeycomb spacer assemblies are set in the top and bottom of the ICV, and limit the effects of impacts on the payload. The honeycomb structure of the aluminum increases the void volume within the ICV, which allows for dilution of any gases diffusing out of or generated within the drums (or other containers).

Three options exist for shipping materials using the TRUPACT-II:

1) 14 55-gallon drums,

2) two standard waste boxes (SWBs), or

3) a ten-drum overpack (TDOP). 
These containers are shown in Figures 2-4. As mentioned before, tens of thousands of 55-gallon drums are earmarked for shipment to WIPP. The SWBs provide a means to ship materials that would not fit into a 55-gallon drum. TDOPs are used primarily for housing drums that have been damaged, or show signs or decay. In light of these options, we now turn to the problem of hydrogen generation within the TRUPACT-II.

\section{Hydrogen Generation}

Transuranic materials emit ionizing radiation which can convert a fraction of nearby water molecules into hydrogen and oxygen gas. If water or some other hydrogenous materials are in close proximity to the transuranic material, hydrogen will be liberated from them by radiolysis. Mixtures of $>5 \%$ hydrogen in air are flammable. To prevent excessive radiolytic hydrogen generation, the TRUPACT-II SARP specifies wattage limits that depend on waste type, container type, and the number of layers of gas confinement (typically plastic contamination control bags). These wattage limits are very conservative and therefore quite restrictive of the amount of transuranic material that can be placed in a single drum or a single TRUPACT-II.

\section{Design Criteria}

\section{Vapor Constraints}

The design criteria to be considered first are the vapor constraints within the Inner Containment Vessel (ICV) of the TRUPACT-II:

1) The maximum $\mathrm{H}_{2}$ concentration in the TRUPACT-II must be maintained below $5 \%$ (by volume) or less. This applies to the ICV and to the "innermost confinement layer." The innermost confinement layer includes sealed bags and metal cans within drums, SWBs, or TDOPs.

2) The largest sealed container allowed is 4 liters.

3) All drums, drum liners, etc. must have a 0.3 -inch hole or equivalent filter vent. These filter vents can be a carbon composite or any nonflammable material that provides HEPA performance.

4) The total internal pressure in the ICV must be less than 50 psig.

5) The concentration of potentially flammable VOCs in the headspace of the ICV must be $500 \mathrm{ppm}$ or less.

The limit on $\mathrm{H}_{2}$ concentration is certainly the most important for hydrogen getters. The successful getter must combine with hydrogen readily enough to keep the concentration of $\mathrm{H}_{2}$ below $5 \%$. Within the headspace of the ICV, adequate diffusion can be assumed. However, maintaining an $\mathrm{H}_{2}$ concentration below $5 \%$ within the innermost confinement layer is a challenge. One way to minimize this concern is to puncture or break the seals of small, sealed containers. Without this step, it is estimated that hydrogen getters would 
only double the number of drums that could be shipped under the current SARP wattage limits. ${ }^{19}$ The reasoning behind this is that the diffusion of hydrogen through a plastic bag (or metal can) and a filter vent is slow enough that a 5\% level of $\mathrm{H}_{2}$ could accumulate inside the bag even though a getter was outside of the drum, reacting with any $\mathrm{H}_{2}$ that diffused out. Hence, some form of repackaging or other means of ensuring that generated $\mathrm{H}_{2}$ reaches the getters will almost certainly be required for a significant portion of drums prior to shipment to WIPP. Repackaging would likely require remote operation (and its associated costs), to protect personnel from exposure to contaminants within the drum.

Another issue is the effect of volatile organic compounds (VOCs) on getters. For some getters, the presence of some organic vapors would poison the mechanism of the getter, rendering it ineffective. Therefore, a successful getter must show itself resistant to such poisoning. At LANL, Mroz ${ }^{7,20}$ is testing one getter, DEB (1,4-bis(phenylethynyl) benzene), for its effectiveness in the presence of various potential poisons. Mroz is also testing the effectiveness of a membrane material that would protect DEB from chlorinated hydrocarbons while not inhibiting the diffusion of $\mathrm{H}_{2}$ to the getter. A broader discussion of specific getter materials and their properties appears in the main text of this work. It should be noted that though the concentration of potentially flammable VOCs in the ICV is limited to $500 \mathrm{ppm}$, nonflammable VOCs are not subject to this limit. Such materials must still be limited for the purpose of protecting human health and the environment. Along these lines, the WIPP Waste Acceptance Criteria ${ }^{21}$ (WAC) gives the following concentration limits for certain VOCs within individual containers: carbon tetrachloride (510 ppm), chloroform (6325 ppm), and methylene chloride (386,500 ppm).

\section{Thermal Constraints}

For heat dissipation, the heat load for the total of all package contents is limited to 40 watts. Only waste type II.2, which is essentially for pipe overpacks, is permitted 40 watts inside a TRUPACT-II. All other waste types (and container types) have wattage limits based on theoretical $\mathrm{H}_{2}$ generation that is far more restrictive. For example, waste type II. 1 (solid inorganics in plastic bags) is allowed 0.2251 watts per drum if there are no closed bags around the waste and 0.1924 if there is a maximum of one closed bag around the waste. A simple conversion shows that less than $0.5 \mathrm{~g}$ of $\mathrm{Pu}-238$ per drum is allowed for this waste type even without any plastic bags. The only waste type in which significantly more watts are allowed is type 1.3 - concreted inorganic particulate waste which is allowed 0.8241 watts per drum. For a list of wattage limits for different waste types, see Table A-1. Clearly, for a TRUPACT-II payload containing 14 drums of common TRU waste, the allowable wattages are nowhere near the maximum of 40 watts. Hydrogen getters placed inside the ICV or inside individual drums would help to resolve the concern behind these low wattage limits.

The other thermal issue affecting getters in the TRUPACT-II is temperature. For regulatory conditions of transport, the maximum drum wall temperature inside the ICV is $130^{\circ} \mathrm{F}\left(55^{\circ} \mathrm{C}\right)$ (including heat from the sun but without an internal heat load). For internal heat loads ranging up to 40 watts, maximum drum wall temperatures are listed in Section 
3.4 of the SARP. Drum wall temperatures under normal operating conditions don't exceed $170^{\circ} \mathrm{F}\left(77^{\circ} \mathrm{C}\right)$ unless all the internal heating is concentrated in one or two drums. During a hypothetical thermal accident event (a fire), the SARP states that the maximum outer drum wall temperature was also $170^{\circ} \mathrm{F}$, based on full-scale fire testing. The lowest temperature for which getters must be safe and effective is $-20^{\circ} \mathrm{F} .{ }^{22}$ However, $-40^{\circ} \mathrm{F}$ is the temperature for testing the effect of cold on package performance. The $-40^{\circ} \mathrm{F}$ value does not give credit for any radiolytic heat generation or insulation of the ICV. Either way, a successful getter must continue to function well below the freezing point of water.

In summary, since the TRUPACT-II could get fairly warm in the desert sun, and could also get quite cold if stuck atop a mountain, the successful hydrogen getter must be able to perform over a range of temperatures: -20 to $170^{\circ} \mathrm{F}$. Possibly, the low temperature requirement will be $-40^{\circ} \mathrm{F}$. Hydrogen storage devices are known to perform well at low temperatures. However, some of these release their stored hydrogen at elevated temperatures. This change in $\mathrm{H}_{2}$ pressure with temperature is exploited to unload the storage materials and prepare for reuse. For this reason, the best solution for the TRUPACT-II may be to use a combination of getters and storage devices.

\section{Packaging Constraints}

The maximum payload weight of the TRUPACT-II is 7,625 lb., including dunnage, padding, lift pallet, slip sheets, etc. Also, individual drums have a weight limit of 1,000 lb. At SRS, $99 \%$ of the drums satisfy this limit.

To keep the center of gravity low, the SARP requires the total weight of the top seven drums (or top SWB) to be less than the total weight of the bottom seven drums (or bottom SWB). Similarly, for TDOPs the top five drums must weigh less than the bottom five. In light of these stipulations, if the getter is heavy, it probably should be placed in the lower portion of the ICV. If it is light, it could possibly be placed in the upper portion of the ICV. For payloads involving 55-gallon drums, the simplest operation is to place the getter in a well-ventilated and dedicated 55-gallon drum. Other implementation options are discussed in greater detail at the end of the Appendix.

A final consideration is that the ICV and OCV of the TRUPACT-II are briefly subjected to vacuum as part of the process of preparing for shipment. ${ }^{23}$ Thus, any proposed getter material must not be damaged or easily volatilized at low pressure.

\section{Content Restrictions}

The fissile material limit (in fissile gram equivalents of ${ }^{239} \mathrm{Pu}$ ) for a payload of drums or SWBs is $\leq 325 \mathrm{~g}$. For individual containers, the limit is $\leq 200 \mathrm{~g}$ per drum and $\leq 325$ per SWB, not to exceed the payload total. An exception to these limits exists for material stored in pipe overpacks. For that case the limit is $\leq 200 \mathrm{~g}$ per pipe overpack and $\leq 2800$ $\mathrm{g}$ per package (of 14 pipe overpacks). The radiation dose rates at the outside surface of 
the TRUPACT-II must be $\leq 200 \mathrm{mrem} / \mathrm{hr}$. The total dose 2 meters from the surface of the TRUPACT-II must be $\leq 10 \mathrm{mrem} / \mathrm{hr}$. To achieve this, the SARP states that neutron moderation or absorption is not expected to be necessary, nor is gamma shielding. Though the alpha dose within a container may be high, alpha particles only travel short distances (on the order of 50 microns or less). Because getter materials are not expected to be touching alpha-emitting substances, the alpha dose is not expected to affect getter materials. For designs that include placing the getter inside drums, radiolysis of getter materials must be considered.

Certain chemical constituents are forbidden from the TRUPACT-II: explosives, nonradioactive pyrophorics, and corrosives. In addition, chemical compatibility between the payload and both the ICV and the o-ring seals must be ensured during transportation, including hypothetical accident conditions. In addition, pressurized containers of any kind shall not be allowed in the payload. Both ICV and OCV are tightly sealed, and seals are tested before shipment. The total volume of residual liquid within payload materials shall be $<1 \%$ (by volume) of the payload container (i.e., the drum, SWB, or TDOP). However, all freestanding water must be removed from the ICV and OCV prior to shipment.

\section{Other Considerations}

Design considerations not mentioned specifically in the SARP appear in the literature. Notably, according to Mroz et al., ${ }^{20}$ the Nuclear Regulatory Commission (NRC) "has rejected the use of catalytic recombiners for removing hydrogen in the TRUPACT-II because of:

1) concerns about possible poisoning of the recombiner by other gases in the headspace.

2) concerns about recombiner performance under low oxygen, even anoxic, conditions (conditions Mroz et al. have observed in matrix depletion experiments).

3) concerns about the possible formation of unacceptable amounts of liquid water within the TRUPACT-II.

4) concerns about recombiner performance in subfreezing temperatures which could possibly result in the formation of an ice coating on the active surface."

In addition, the heat generated by a getter would be a concern if it melted the getter or decreased its effectiveness.

Obviously, a successful getter would have to resolve these concerns favorably. Currently, the use of getters or recombiners is not supported by the SARP. However, the use of catalysts is mentioned as a possibility, along with slight modification to the aluminum honeycomb structure to accommodate them. In addition, other requests for special considerations have been approved and incorporated into the SARP: 
1. New code for tritium-titanium sponges.

2. Non-carbon filters for vents.

3. Filtered, heat-sealed bags.

Implementation

Many options exist for ways to implement hydrogen getters in TRUPACT-IIs. One way would be to set the getter in a single, dedicated 55-gallon drum with plenty of holes or filter vents for adequate diffusion. This drum would be placed in the top or bottom set of drums, depending on its weight relative to the other drums. Some getters can be formed into small pellets, and thus could be supplied in many different shapes and sizes. Rods or screened-in columns of getter-filled material could be placed laterally between drums in the 14-drum arrangement, or just outside SWBs or TDOPs. Additionally, the payload pallet at the bottom of the ICV, or a thin slab on top of the payload could be loaded or back-filled with getter material. For particularly high-wattage drums, getter materials could be placed inside the drums. The preferred implementation geometry should become clearer as other hurdles for the use of getters are passed.

The amount transuranic material placed in the TRUPACT-II is limited to a total thermal load of 40 watts per payload. A component of transuranic waste, $\mathrm{Pu}-238$, has a specific power of 0.56 watts/gram. Thus, the maximum amount of $\mathrm{Pu}-238$ in a TRUPACT-II payload is $71 \mathrm{~g}$. Even if this plutonium were evenly divided into 14 drums to form a TRUPACT-II payload, it would contain more than 10 times the watts per drum allowed in most of the SARP's analytical shipping categories (listed in Table A-1). Shipping TRUPACT-II payloads containing Pu-238 levels near the maximum would reduce the number of shipments to WIPP needed. 
Table A-1. Wattage Limits per 55-Gallon Drum for Analytical Shipping Categories.

\begin{tabular}{ccc} 
Waste Type* & Watts (0 confinement layers) & Watts (1 confinement layer) \\
\hline I.1 & 0.2060 & 0.1797 \\
I.2 & 0.2536 & 0.2212 \\
I.3 & 0.8241 & 0.7189 \\
II. & 0.2251 & 0.1924 \\
II. & 40 & \\
III.1 & 0.1126 & 0.0962
\end{tabular}

*Waste types are defined as:

I.1 - Adsorbed, absorbed, or solidified inorganic liquid.

I.2 - Soils, solidified particulates, or sludges formed from precipitation.

I.3 - Concreted inorganic particulate waste.

II. 1 - Solid inorganic materials in plastic bags.

II. 2 - Solid inorganic materials in metal cans.

III. - Solid inorganic materials. 


\section{Attachment 1: Gettering Capacity Needed}

The ICV of the TRUPACT-II is 6 feet in diameter and 8 feet tall. This corresponds to a volume of $226 \mathrm{cu}$. ft. or 6400 liters. However, the $\mathrm{SARP}^{[1, \mathrm{p} .3-\mathrm{s} 0 \mathrm{j}}$ assumes that a TRUPACT-II containing 14 drums has a void volume of only 2,450 liters. This is mostly due to assuming the drums contain no void volume, though historically they have had an average void volume of $50 \%$. Using the conservative SARP value, the ICV contains

$\mathrm{N}=(1 \mathrm{~atm})(2450 \mathrm{l}) /(0.0821)(294 \mathrm{~K})=102$ moles of gas initially $\left(\right.$ at $\left.70^{\circ} \mathrm{F}=21^{\circ} \mathrm{C}\right)$.

The radiolytic generation of hydrogen reaches $5 \%$ by volume after the production of $0.05=\mathrm{x} /(102+\mathrm{x})$ $\mathrm{x}=5.4$ moles of hydrogen $\left(\mathrm{H}_{2}\right)$.

The SARP wattage limits for different waste materials types are given in Table 1. Using the appropriate $\mathrm{G}$ values (amount of hydrogen generated per $100 \mathrm{eV}$ of radiolytic energy) and $\mathrm{F}$ values (fraction of radiation absorbed by target material), these wattage limits ensure that $\mathrm{H}_{2}$ generated in 60 days is less than 5.4 moles. However, it is desired to put the maximum of 40 watts within a TRUPACT-II payload. For a payload of 14 drums, this maximum corresponds to 2.86 watts/drum. This is an increase of 3.5 to 25 times the current SARP limits (in Table A-1) for all waste types except II.2. (Waste type II.2 essentially applies to pipe overpacks.) In this example, waste type II.1 is used as the median of the wattage limits in Table A-1 - 0.2251 watts/drum for drums with no internal layers of confinement. Maximizing the transuranic content in a payload (of this type) yields a multiple of $(2.86 / 0.2251)=12.7$. In other words, $\mathrm{H}_{2}$ getters would need to absorb or recombine 12.7 times the amount of $\mathrm{H}_{2}$ required to produce a $5 \%$ mixture. Therefore, the $\mathrm{H}_{2}$ gettering capacity needed is $12.7 \times 5.4$ moles $\mathrm{H}_{2}=68.6 \mathrm{moles}_{2}$, or an average of 1.14 moles/day for 60 days. This provides somewhat of an upper bound for the amount of gettering needed. For different waste types, different amounts of getter material would be required. 
Attachment 2: Heat Generated by Getter

From Attachment 1, a typical upper bound for $\mathrm{H}_{2}$ generation is $1.1 \mathrm{~mole}_{2}$ /day for a waste type having 40 watts of decay heat inside a TRUPACT-II. Of the different getter mechanisms for capturing or combining $\mathrm{H}_{2}$, the one that produces the most heat is combining the $\mathrm{H}_{2}$ with $\mathrm{O}_{2}$ to form $\mathrm{H}_{2} \mathrm{O}$. This reaction produces $68 \mathrm{kcal} / \mathrm{mole} \mathrm{H}_{2}$. Therefore, a typical upper bound for heat generation for a $\mathrm{H}_{2}$ getter is

$\left(68 \mathrm{kcal} / \mathrm{mole}_{2}\right)\left(1.1 \mathrm{~mole} \mathrm{H}_{2} /\right.$ day $)($ day $/ 24 \mathrm{hr})(\mathrm{hr} / 3600 \mathrm{sec})(1000 \mathrm{cal} / \mathrm{kcal})(4.184 \mathrm{~J} / \mathrm{cal})$ $=3.6 \mathrm{~J} / \mathrm{sec}=3.6$ Watts.

Getters that do not produce water would most likely produce significantly less heat. 


\section{References}

1. Safety Analysis Report for the TRUPACT-II Shipping Package, Revision 17, Docket Number 71-9218, Westinghouse Electric Corporation, Waste Isolation Division, Carlsbad, NM, March 1998.

2. Kosiewicz, S.T., Nuclear Technology, 54, "Gas Generation from Organic Transuranic Wastes. I. Alpha Radiolysis at Atmospheric Pressure," 92-99 (July 1981).

3. Kazanjian, A.R., P.M. Arnold, W.C. Simmons, E.L. D'Amico, Gas Generation Results and Venting Study for Transuranic Waste Drums, RFP-3739, Rockwell International, Rocky Flats Plant, Golden, CO, Sept. 23, 1985.

4. Ryan, J.P., Radiogenic Gas Accumulation in TRU Waste Storage Drums, DP-1604, Savannah River Laboratory, January 1982.

5. Reed, D.T., J. Hoh, J Emery, S. Okajima, and T. Krause, Gas Production Due to Alpha Particle Degradation of Polyethylene and Polyvinylchloride, ANL-97/7, Argonne National Laboratory, July 1998.

6. Supporting Documentation for TRU Waste Disposition Program, Westinghouse Savannah River Co. and Vitech Corp., WSRC-RP=96-488, Oct. 24, 1996.

7. Mroz, E.J., D. Finnegan, P. Noll, S. Djordjevic, C. Loehr, V. Banjac, J. Weinrach, J. Kinker, and M.J. Connolly, Increasing TRUPACT-II Wattage Limits: Hydrogen GValues and Getters, Waste Mgmt. '99 Symposium, Tucson, AZ, Mar. 1999.

8. Nigrey, P.A., White Paper on the Use of Hydrogen Getters in Transportation Environments (DRAFT), SNL Transportation Technology, 2/12/99.

9. Henrie, J.O. and A.K. Postma, Lessons Learned from the Hydrogen Generation and Burning During the TMI-2 Event, GEND-061, May 1987.

10. Engelhard Systems, 101 Wood Ave., Iselin, New Jersey 08830.

11. Huston, E.L. and G.D. Sandrock, Journal of Less-Common Metals, 74, "Engineering Properties of Metal Hydrides," 435-443 (1980).

12. Baldwin, D.L., G.W. Hollenberg, C.M. King, and R.N. Johnson, PNNL Composite Getter for Hydrogen, Pacific Northwest National Laboratory, 28IC280848 (Feb. 1999).

13. Schicker, J.R., personal communication, January 1999.

14. Ho, W.S.W. and K.K. Sirkar, Membrane Handbook, Van Nostrand Reinhold, New York, (1992). 
15. Heung, L.K., G.G. Wicks, and M.W. Lee, Composition For Absorbing Hydrogen From Gas Mixtures, Patent Pending, assigned to Westinghouse Savannah River Company.

16. Heung, L.K., personal communication, Dec. 1998.

17. Mroz. E.J., personal communication, March 1999.

18. Backgrounder on the Waste Isolation Pilot Plant, WIPP Backgrounder No. 11, July 29, 1998.

19. Connolly, M.J. and S.T. Kosiewicz, TRU Waste Transportation - the Flammable Gas Generation Problem, Fourth Biennial Mixed Waste Symposium, Baltimore, MD, Aug. 18-21, 1997.

20. Mroz, E.J., C.P. Liebman, and S.T. Kosiewicz, Increasing TRUPACT-II Wattage Limits: Two Technical Approaches, Waste Mgmt '97 Conf., Tucson, AZ, Mar. 2-7, 1997.

21. Waste Acceptance Criteria for the Waste Isolation Pilot Plant, DOE/WIPP-069, April 1996.

22. U. S. Nuclear Regulatory Commission, Packaging and Transportation of Radioactive Material, Title 10 of the Code of Federal Regulations, Part 71, $\$ 71$ (b) and Part 71, $\S 71$ (c)2, Washington, D. C., 1995.

23. TRUPACT-II Procedures and Maintenance Instructions. 